\title{
Microgrids planning for rural electrification
}

\author{
Kanika Yon \\ Marie-Cecile Alvarez-Herault \\ Bertrand Raison \\ Univ. Grenoble Alpes, CNRS, Grenoble INP*, G2Elab, F- \\ 38000 Grenoble, France \\ *Institute of Engineering Univ. Grenoble Alpes \\ Grenoble, France \\ Marie-Cecile.Alvarez-Herault@g2elab.grenoble-inp.fr
}

\author{
Kimsrornn Khon \\ Vannak Vai \\ Long Bun \\ Electrical and Energy Engineering Department, \\ Energy Technology and Management Research Unit, \\ Institute of Technology of Cambodia \\ Phnom Penh, Cambodia \\ kimsrornn.khon@g2elab.grenoble-inp.fr
}

\begin{abstract}
A large part of the population living in rural areas of developing countries does not have access to electricity because the investment is high due to the low population density and some households cannot afford the high electricity bill. Therefore, some of them invest in small photovoltaic generation units called Solar Home System (SHS). The objective of this paper is to provide a microgrid planning methodology including grid design, optimal location and sizing of SHSs and battery energy storage in a context of rapid and low-cost electrification while waiting for a potential connection to the MV distribution grid. To solve these optimization problems, the minimum spanning tree algorithm and a genetic algorithm are selected and tested on a rural village in Cambodia.
\end{abstract}

Index Terms- Electrification, Genetic Algorithm, Minimal Spanning Tree, Microgrids.

\section{INTRODUCTION}

In a developing country like Cambodia, the percentage of rural electrification connected to an existing grid is still low (64.5\%) [1]. Investors and Independent Power Producers (IPPs) are not interested in investing in rural electrification because it requires big investments and long payback period due to the low load density. Therefore, many households have decided to switch to Solar Home System (SHS) in order to have access to electricity for basic usage (such as charging phones, TV, fans). The Cambodian government is promoting and encouraging the development of electrification through several policies to provide an access to the grid to at least $70 \%$ of consumers by 2030 [2]. In the short term, the microgrid is an effective solution to meet this objective because it can be implemented quickly and at a reasonable cost. In the long term, if a connection to a new MV distribution network through an $\mathrm{MV} / \mathrm{LV}$ substation becomes possible, this microgrid could provide some services such as flexibility and stability support. Therefore, it is necessary to develop a microgrid planning methodology based on optimization techniques to find the best grid topology and optimal location and sizing of PV and storage that can provide economic, environmental and technical benefits. Many articles in the literature have worked on microgrids for rural electrification, as summarized in Table I, but none of them propose an integrated planning approach from topology design, selection and sizing of generation assets, and cost calculation.

TABLE I. LITERATURE REVIEWS OF MICROGRIDS FOR RURAL ELECTRIFICATION

\begin{tabular}{|c|c|}
\hline Contributions & Ref. \\
\hline $\begin{array}{l}\text { Automated electrification planning tool } \\
\text { minimizing cost between: grid extension, off- } \\
\text { grid microgrids or standalone system based on } \\
\text { the lowest cost system designs. } \\
\text { - Drawback: only one generationsite fixed in } \\
\text { each MG }\end{array}$ & [3] \\
\hline $\begin{array}{l}\text { Method: shortest path and first-fit bin-packing } \\
\text { for length minimization and load balancing; } \\
\text { PV arbitrary located, one decentralized three- } \\
\text { phase battery located using a genetic } \\
\text { algorithm (GA) and a centralized battery at } \\
\text { the MV/LV substation. } \\
\text { Drawback: grid-connected topology not full } \\
\text { time autonomous. }\end{array}$ & {$[4]$} \\
\hline $\begin{array}{l}\text { Method: net present value minimization of } \\
\text { different rural electrification schemes: hybrid } \\
\text { microgrid and conventional grid extension } \\
\text { using HOMER } \\
\text { - Drawback: no optimal design of the LV grid } \\
\text { topology }\end{array}$ & $\begin{array}{c}{[5]-} \\
{[7]}\end{array}$ \\
\hline $\begin{array}{l}\text { - Method: LCOE optimization and sensitivity } \\
\text { analysis of hybrid microgrid for rural } \\
\text { electrification using different algorithms: } \\
\text { HOMER, linear programming (LP), Mixed } \\
\text { Integer Linear Programming (MILP), } \\
\text { Simulated Annealing (SA), GA, Particle }\end{array}$ & $\begin{array}{l}{[8]-} \\
{[14]}\end{array}$ \\
\hline
\end{tabular}




\begin{tabular}{|c|c|}
\hline $\begin{array}{l}\text { Swarm Optimization (PSO), Grasshopper } \\
\text { Optimisation Algorithm (GOA), Converged } \\
\text { Elephant Herding Optimization (cEHO) } \\
\text { - Drawback: Single node system without LV } \\
\text { grid topology }\end{array}$ & \\
\hline $\begin{array}{l}\text { - Method: current unbalance factor } \\
\text { minimization in LV grid using different } \\
\text { algorithms: PSO, GA, combinatorial phase } \\
\text { swapping } \\
\text { - Drawback: no optimal radial grid topology } \\
\text { and integration of DERs }\end{array}$ & $\begin{array}{c}{[15]-} \\
{[17]}\end{array}$ \\
\hline $\begin{array}{l}\text { - Method: optimal sizing of the microgrid } \\
\text { equipment from a set of commercial models } \\
\text { available in the market: Battery Energy } \\
\text { Storage (BES) and wind turbine. } \\
\text { - Drawback: no optimal sitting of PV and/or } \\
\text { BES and design of the LV grid topology }\end{array}$ & [18] \\
\hline $\begin{array}{l}\text { - Method: optimal connection of the AC and } \\
\text { DC layers; optimal number, size, and } \\
\text { locations of the interlinking converters (ICs) } \\
\text { of microgrids. } \\
\text { - Drawback: no integration of the optimal } \\
\text { sitting and sizing of PV and/or BES }\end{array}$ & [19] \\
\hline
\end{tabular}

In this paper, we propose a planning methodology ranging from the design of the network to the sizing of generations and storage. In section II, we present the microgrid planning concept proposed and the hypotheses taken. Then in section III, the mathematical formulations are provided as well as the chosen solving algorithms. In section IV, the planning methodology is applied to a real test case in Cambodia. Some conclusions and perspectives for future works are presented in section $\mathrm{V}$.

\section{MICROGRID PLANNING CONCEPT}

\section{A. Microgrid Concept}

The proposed microgrid, shown in Fig.1, consists of an AC LV distribution network, some loads, PV, batteries and a diesel generator. Two types of batteries are considered: decentralized (resp. deBES) and centralized (resp. ceBES). The PV is systematically associated with a deBES as a single system called PV-deBES and connected to some loads. The ceBES is associated with a diesel generator to impose the voltage and ensure the balance between production and consumption in the whole system. They are located at the future position of an $\mathrm{MV} / \mathrm{LV}$ substation where the $\mathrm{LV}$ grid would be connected to the MV grid if deployed. It is assumed that all PV-deBES are identical in terms of generated, loaded and unloaded power and capacity. The control strategy of the deBES aims at optimizing the PV self-consumption. Its charging and discharging power curve is the result of predictions and is updated in real time in case of changes in production or consumption schedules. This control is based on the following rules: during the day, the load is supplied by the
PV and any excess energy is stored in the deBES (and in the ceBES if necessary); during the night, the load is supplied by the deBES. If the deBES is totally discharged and more power is needed, the load will be supplied by the ceBES. In case both deBES and ceBES are totally discharged, the remaining energy needed is supplied by the Diesel Generator. The latest can also be oversized to supply some customers in case of failures of some PVs.

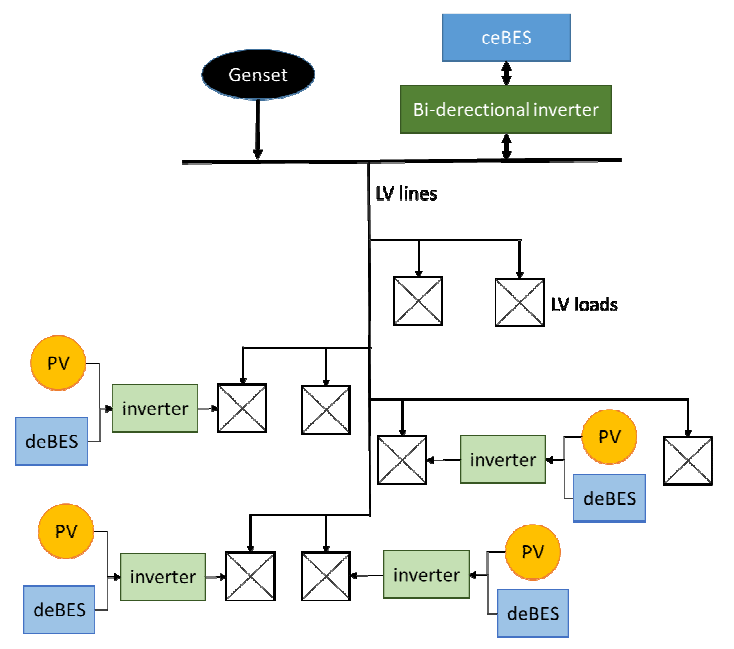

Figure 1. Microgrid structure

\section{B. Hypothesis Considered}

In this paper, we suppose that the location of LV customers, their load profile and the location of the future MV/LV substation are known. Energy Management System (EMS) solutions are already developed by several companies [20] in order to control the charge and discharge of deBES. So we will not focus on their control but rather on their sitting and sizing. Consequently, the deBES power curve is considered as an input for the microgrid planning methodology and defined as the power required to maximize self-consumption (with a minimal amount of PV) ensuring that the total energy charged during 24 hours is equal to the total energy discharged. Based on a normalized load curve from real measurements in Cambodia during a cold day in December 2016 [2] and a normalized PV curve from the NASA [2], the PV maximal production is increased until the total energy charged and discharged by the battery during 24 hours are equal. In a first approximation, we supposed that the deBES is a daily storage with the same daily profile all the year in rural areas. Indeed, there are two seasons in Cambodia: the dry season where the consumption is increased during the day compared to the rainy season due to the use of fans. As the PV production also increases during the dry seasons (biger solar radiation), we can assume that the difference between production and consumption is almost constant during the year. Fig. 2 gives the considered deBES normalized power curves used for the sitting and sizing of PV-deBES. The excess of PV is stored in the ceBES. 


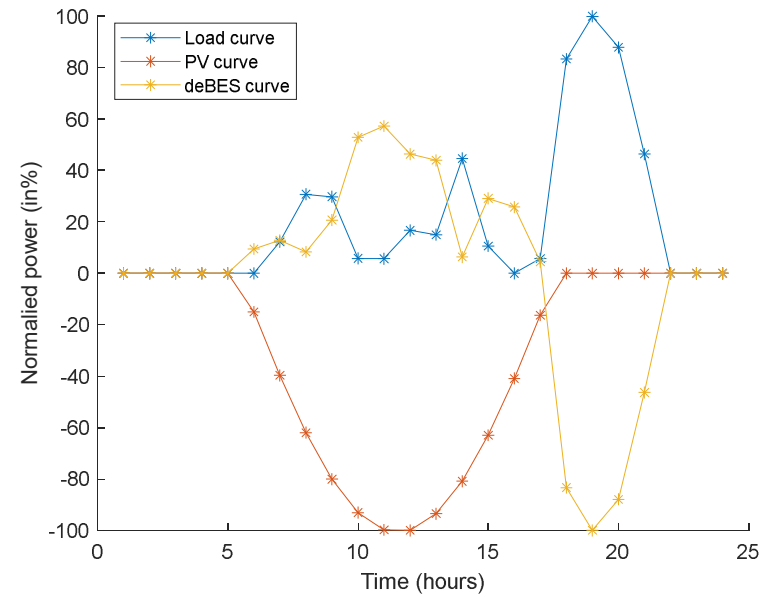

Figure 2. Daily load curve, PV curve and deBES curve in rural area

\section{Microgrid Planning Methodology}

The microgrid planning methodology includes the following 6 steps: (1) construction of the optimal grid topology, (2): selection and sizing of PV-deBESs (maximum power calculation), (3) sizing of deBES capacity, (4) sizing of ceBES (maximum power and capacity), (5): sizing of diesel generator (maximum power), and (6) cost calculation.

\section{PROBLEM FORMULATION AND RESOLUTION}

\section{A. Step1: Topology Optimization Problem}

The LV network is a three-phase system with single-phase loads. The objective is to find the radial topology, which minimizes the phase imbalance and the total system length. The phase balancing optimization problem can be written with equation (1) to (5) where (1) is the objective function subject to the constraints (2) to (4). This problem is solved using mixed integer linear programming (MILP) with Matlab. The length minimization consists in finding the minimal spanning tree, which is done using the Kruskal algorithm [21].

$$
\begin{gathered}
\min _{x}\left(\sum_{j=1}^{3} \varepsilon^{+}(j)+\mathcal{E}^{-}(j)\right) \\
\sum_{n=1}^{N} P_{l}(n) \times x(n, j)-\mathcal{E}^{-}(j)+\varepsilon^{+}(j) \leq \frac{P_{t o t}}{3}, \forall j=1: 3 \\
\sum_{j=1}^{3} x(n, j)=1, \forall n=1: N \\
0 \leq x(i, j) \leq 1, \forall j=1: 3 \& i \in[1 ; N] \\
0 \leq \mathcal{E}^{-}(j) \leq+\infty, \forall j=1: 3 \\
0 \leq \varepsilon+(j) \leq+\infty, \forall j=1: 3
\end{gathered}
$$

$x(i, j)=1$ if cluster $\mathrm{i}$ belongs to phase $\mathrm{j}$ and 0 otherwise; $\varepsilon^{+}(j)$ is the positive difference variables of phase $\mathrm{j} \mathcal{E}^{-}(j)$ is the negative difference variable of phase $\mathrm{j} ; P_{l}(i)$ is the maximal power of load i; $P_{t o t}$ is the total power consumed by the loads and $\mathrm{N}$ is the number of nodes of the power systems.

\section{B. Step 2: Optimal Sitting and Sizing of PV-deBES (Maximal Powers)}

The optimization problem consists in finding the location of the PV-deBES and their respective installed capacity in order to maximize the local consumption (i.e. minimize the energy coming from the slack bus which represents the location of the diesel generator and the ceBES) and minimize the power losses in the whole system. The multi-objective function to minimize is expressed by equation (5) and the decision variables in vector $X$ (equation (6)). $X$ consists of three subvectors of size $3 \mathrm{~N}+2, \mathrm{~N}$ being the number of nodes of the network.

$$
\begin{gathered}
\min _{X}\left(a \times \sum_{t=1}^{24} \sum_{j=1}^{3} P_{\text {slack }, t, j}^{2}(X)+b \times \sum_{t=1}^{24} \sum_{j=1}^{3} P_{\text {loss }, t, j}(X)\right) \\
X=\left[\begin{array}{c}
L_{P V} \\
P_{P V \max } \\
P_{\text {deBES max }}
\end{array}\right]
\end{gathered}
$$

For $\mathrm{n}=1 \ldots \mathrm{N}, L_{P V}((j-1) \times N+n)=1$ if a PV-deBES at node $\mathrm{n}$ and phase $\mathrm{j}$ and 0 otherwise; $X(3 N+1)=P_{P V \max }$ and $X(3 N+2)=P_{d e B E S \max } \cdot P_{P V \max }$ is the maximal power produced by the $\mathrm{PV} ; P_{d e B E S \text { max }}$ is the maximal charge and discharge of the deBES.

This optimization problem is subject to the following constraints:

$$
\begin{aligned}
& 0.9 \leq V(n, j) \leq 1.1, \mathrm{n}=1 \ldots \mathrm{N} \& \mathrm{j}=1 \ldots 3 \\
& 0 \leq I(l, j) \leq I_{\max }(l, j), \mathrm{l}=1 \ldots \mathrm{L} \& \mathrm{j}=1 \ldots 3
\end{aligned}
$$

$\mathrm{P}_{\text {slack,t,j }}$ is the power generated at the slack bus of the power system at time $t$ for phase $\mathrm{j} ; \mathrm{P}_{\text {loss,t,j }}$ are the power losses of the power system at time $\mathrm{t}$ for phase $\mathrm{j}$; $\mathrm{a}$ and $\mathrm{b}$ are weighted coefficients; $\mathrm{L}$ is the number of lines of the power systems; $\mathrm{V}(n, j)$ is the voltage at node $n$ and phase $j ; I(1, j)$ is the current through line 1 in phase $j ; I_{\max }(1, j)$ is the maximal current through line 1 of phase $\mathrm{j}$.

$P_{\text {slack,t.j, }}, P_{\text {loss,t.j, }}, V(n, j)$ and $I(1, j)$ are computed using unbalanced Bakward Forward based loadflow [22].

To solve this nonlinear problem subjected to non-linear constraints with both binary and continuous variable, the Genetic Algorithm (GA) has been selected. This method is known to solve complex problems in Power Distribution Planning (PDP) problem like location and size of substations, feeders and productions in order to minimize total power loss cost, investment cost and total cost [23]. In our case, the settinhngs are 200 individuals and a maximum number of 500 generations to avoid the interruption of simulations before the convergence of the algorithm. Several combinations of weighting factors have been tested and we noticed is that the bigger the weighting factor on the power exchange with the slack part is $(a>b)$, the bigger the fitness will be. After simulating several values of $a$ and $b$, the best combination was $a=0$ and $b=1$ meaning that focusing on power losses 
minimization has a greater impact on cost and technical constraints since it optimizes local consumption.

\section{Step 3: Capacity Computation of the deBES}

Let's $X_{s o l}$ be the solution vector of the previous optimization problem. The required capacity of deBES is given by equation (9).

$$
\begin{aligned}
& C_{\text {deBES }}=\frac{\max \left(E_{\text {deBES }}\right)-\min \left(E_{\text {deBES }}\right)}{1-S O C_{\max }} \\
& \operatorname{deBES}(t)=\operatorname{deBES}_{\text {norm }}(t) \times X_{\text {sol }}(3 N+2) \\
& E_{\text {deBES }}(t)=\int_{0}^{t} \operatorname{deBES}(u) d u, \mathrm{t}=1: 24
\end{aligned}
$$

$\operatorname{deBES}_{\text {norm }}(t)$ is the normalized power of the deBES at time $\mathrm{t}$; $\operatorname{deBES}(t)$ is the power of the deBES at time $\mathrm{t}$ (in $\mathrm{kW}$ ); $E_{\text {deBES }}(t)$ is the state of charge of the battery at time $\mathrm{t} ; C_{\text {deBES }}$ is the required capacity of the deBES (in $\mathrm{kWh}$ ) and $S O C_{\max }=80$ $\%$.

\section{Step 4: Optimal Sizing of ceBES}

The loadflow of the system for the whole year is run using the annual load curve (repetition of the daily load curve), $X_{\text {sol }}$ and the yearly solar radiation from Homer [24] in order to get the yearly profile of energy exchange with the ceBES. The required capacity, $C_{c e B E S}$, is given by equation (12).

$$
\begin{gathered}
C_{c e B E S}=\frac{\max _{t}\left(E_{c e B E S}(t)\right)-\min _{t}\left(E_{c e B E S}(t)\right)}{1-S O C_{\max }} \\
E_{c e B E S}(t)=\int_{0}^{t} P_{c e B E S}(u) d u, \mathrm{t}=0: 8760 \\
P_{c e B E S \max }=\max _{t}\left|P_{c e B E S}(t)\right|
\end{gathered}
$$

$E_{\text {ceBES }}(t)$ is the state of charge of the battery at time t; $P_{c e B E S}(t)$ is the yearly charge and discharge schedule of ceBES; $P_{c e B E S \max }$ is the maximal charged and discharged power of the ceBES (in $\mathrm{kW}$ ).

\section{E. Step 5: Sizing of the Diesel Generator}

The diesel generator will be used to supply the remaining energy needed from the slack bus if the ceBES cannot provide it. We chose to oversize its capacity by an arbitrary value of $50 \%$ of the total power because the disel generator is not only used as a slack bus but also as a backup generator in case some PVs do not work or when the PV production is low due to bad weather. Therefore, the energy that needs to be supplied by the diesel generator per year is given by equation (16).

$$
C_{\text {gen }}=\sum_{t=0}^{8760}\left(\sum_{j=1}^{3} P_{\text {slack }, t, j}-P_{\text {ceBES }}(t)\right)
$$

$$
P_{\text {gen } \max }=0.5 \times P_{\text {tot }}
$$

$P_{\text {gen } \max }$ is the yearly power of the diesel generator (in $\mathrm{kW}$ ); $C_{g e n}$ is the total energy supplied by the diesel generator.

\section{F. Step 6: Cost Computation}

The discounted cost method over the planning period ( $\mathrm{T}$ years) is used to assess the cost of the designed microgrid (equation (18)). It takes into account the capital expenditure (CAPEX, equation (19)) and the operational expenditure (OPEX, equation (20)). We assumed that the CAPEX is spent on the first year of planning period and takes into account only the component costs (PV, BES, inverter and diesel generator). The OPEX consists of the maintenance costs and the cost of the energy provided by the diesel generator when PV and BES are not enough.

$$
\begin{gathered}
C_{\text {total }}=C A P E X+O P E X \\
C A P E X=C_{P V}+C_{B E S}+C_{\text {inverter }}+C_{\text {gen }} \\
O P E X=\sum_{t=0}^{N} \frac{C_{\text {elec }} \times E_{\text {netw }}(t)+C_{\text {maintenance }}}{(1+r)^{t}}
\end{gathered}
$$

With: $C_{P V}$, the CAPEX of installed PVs; $C_{B E S}$, the CAPEX of installed batteries (both decentralized and centralized); $C_{\text {inverter }}$, the CAPEX of inverters; $C_{g e n}$, the CAPEX of the diesel generator; $C_{\text {elec }}$ is the electricity price in $(\$ / \mathrm{kWh})$; $E_{\text {netw }}(t)$ is the energy exchanged with the slack bus supplied by the diesel generator at year $\mathrm{t}$ (in $\mathrm{kWh}$ ); $C_{\text {maintenance }}$ is the maintenance cost of $\mathrm{PV}, \mathrm{BES}$ and inverter (in $\mathrm{k} \$ / \mathrm{kW}$ ); $\mathrm{r}$ is the discount rate (in \%).

\section{CASE STUDIED}

A village of Bavel in Battambang province in Cambodia is selected to be the case study in order to test the proposed method. In developing countries, the households are almost all single - phase, located along the road in a rural area. The total active power is $24 \mathrm{~kW}$ with a power factor (pf) of 0.95 . The poles are numbered from 1 to 22 with a distance between poles of $40 \mathrm{~m}$. The technical and economic data used in this case studied are provided in Table II.

TABLE II. TECHNICAL AND ECONOMIC PARAMETERS

\begin{tabular}{|c|c|}
\hline Parameter & Market prices \\
\hline Planning period $(\mathrm{T})$ & 15 years \\
\hline $\mathrm{ABC}-2 \times 4 \mathrm{~mm} 2$ cable cost $(\mathrm{k} \$ / \mathrm{km})$ & $0.6[2]$ \\
\hline $\mathrm{ABC}-2 \times 35 \mathrm{~mm} 2$ cable cost $(\mathrm{k} \$ / \mathrm{km})$ & $1[2]$ \\
\hline $\mathrm{ABC}-2 \times 50 \mathrm{~mm} 2$ cable cost $(\mathrm{k} \$ / \mathrm{km})$ & $1.6[2]$ \\
\hline $\mathrm{ABC}-2 \times 70 \mathrm{~mm} 2$ cable cost $(\mathrm{k} \$ / \mathrm{km})$ & $2[2]$ \\
\hline $\mathrm{ABC}-2 \times 95 \mathrm{~mm} 2$ cable cost $(\mathrm{k} \$ / \mathrm{km})$ & $3[2]$ \\
\hline
\end{tabular}




\begin{tabular}{|c|c|}
\hline Actualization rate $(\%)$ & 6 \\
\hline Electricity cost $(\$ / \mathrm{kWh})$ & $0.27[25]$ \\
\hline PV panel $(\mathrm{k} \$ / \mathrm{kW})$ & $0.6[26]$ \\
\hline BES $(\mathrm{k} \$ / \mathrm{kWh})$ & $0.105[26]$ \\
\hline Inverter $(\mathrm{k} \$ / \mathrm{kW})$ & $0.3[26]$ \\
\hline Bi-directional inverter $(\mathrm{k} \$ / \mathrm{kW})$ & $1.155[2]$ \\
\hline $\mathrm{PV}+$ BES maintenance cost $(\mathrm{k} \$ / \mathrm{kW})$ & $0.0115[27]$ \\
\hline Inverter maintenance cost $(\mathrm{k} \$ / \mathrm{kW})$ & $0.023[27]$ \\
\hline Diesel generator $(\$ / \mathrm{kW})$ & $500[28]$ \\
\hline
\end{tabular}

\section{A. Network optimization}

The topology found after running the Kruskal algorithm is depicted in Fig.3. The pole to pole connections are in $50 \mathrm{~mm}^{2}$ aluminum and the load to pole connections are in $4 \mathrm{~mm}^{2}$ which are typical conductors sections in Cambodia. The total length of the network is $3.5 \mathrm{~km}$ and the unbalance factor is 0.9 $\%$ (maximal difference between 2 phases).

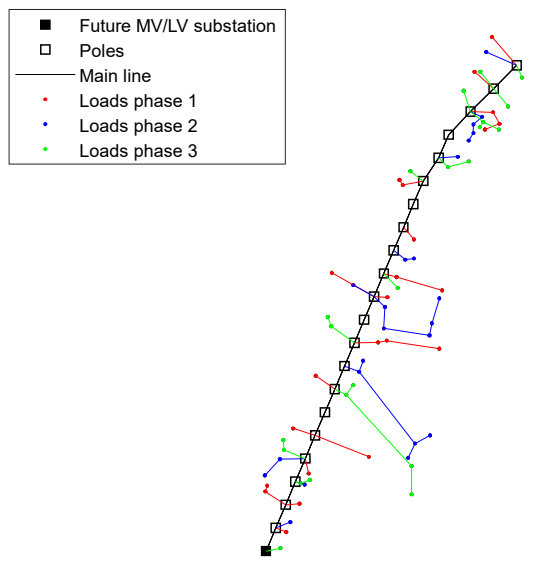

Figure 3. Minimum spanning tree connection topology (one color per phase)

\section{B. "On-grid" vs "off-grid"}

In the "On-grid" case, we assume that the network is connected to a MV grid through a MV/LV transformer and no integration of PV and BES. There is no maintenance cost and the CAPEX contains only the line cost. The OPEX is mainly the electricity bill over $\mathrm{T}$ years with the discount rate of $\mathrm{r} \%$. In the "off-grid" case, we assume that the proposed microgrid planning methodology is used. CAPEX includes the cost of all required components and the cable cost. OPEX is the combination of the electricity bill (fuel cost) provided by the diesel generator over $\mathrm{T}$ years with the discount rate of $\mathrm{r} \%$ and the maintenance cost. The results are provided in Fig. 4 and Table III. It can be noticed that power losses in the "off-grid" solution are close to 0 because of the optimization of local consumption. Finally, Table IV compares the "on-grid" and "off-grid" solution in terms of cost and autonomous time. The cost of the microgrids option is half of the "on-grid" one showing the interest of such a solution. In reality, this margin will be reduced considering the cost of the BES control. The "off-grid" option is the only one to ensure an autonomous time of $100 \%$ versus $37.5 \%$ in the "on-grid" option which corresponds to period where the consumption is equal to 0 .

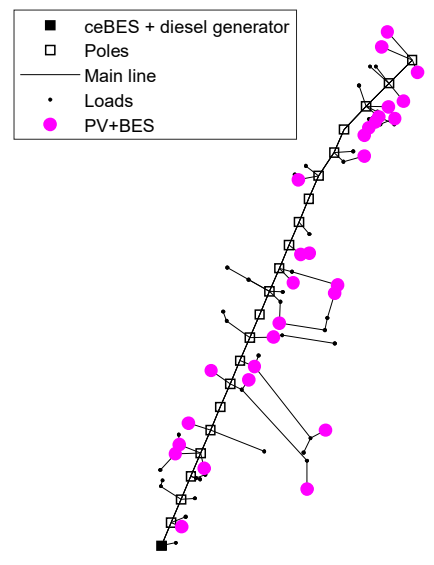

Figure 4. PV and BES sitting in the network

TABLE III. “OFF-GRID” RESULTS

\begin{tabular}{|c|c|}
\hline Parameters & Value \\
\hline Number of PV-deBES and inverters & 29 \\
\hline Number of bidirectional inverters & 1 \\
\hline$P_{P V \max }(\mathrm{kW})$ & 0.5 \\
\hline$P_{\text {deBES max }}(\mathrm{kW})$ & 0.77 \\
\hline$C_{\text {deBES }}(\mathrm{kWh})$ & 3.06 \\
\hline$P_{c e B E S \max }(\mathrm{kW})$ & 1.16 \\
\hline$C_{c e B E S}(\mathrm{kWh})$ & 3.22 \\
\hline$P_{g e n \max }(\mathrm{kW})$ & 11.8 \\
\hline Line cost $(\mathrm{k} \$)$ & 4.58 \\
\hline
\end{tabular}

TABLE IV. “ON-GRID” RESULTS

\begin{tabular}{|c|c|c|}
\hline Parameters & On-Grid & Off-grid \\
\hline $\begin{array}{c}\text { Annual losses (MWh) } \\
\text { Annual energy required at the } \\
\text { slack bus (MWh) }\end{array}$ & 0.41 & 0.067 \\
\hline CAPEX (k\$) & 43.6 & 4.18 \\
\hline OPEX (k\$) & 102.39 & 35.99 \\
\hline Discount cost (k\$) & $\mathbf{1 0 6 . 9 7}$ & $\mathbf{5 6 . 0 8}$ \\
\hline Autonomous time (in \% of T) & $\mathbf{3 7 . 5}$ & $\mathbf{1 0 0}$ \\
\hline
\end{tabular}




\section{CONCLUSION}

In this paper, we propose a comprehensive microgrid planning methodogy for fast and cheap electrification. Several optimization algorithms are used to find the optimal network topology as well as the sitting and sizing of PV and BES. The main drawback of this methodology is the GA. It required several simulations with different values of the weighting factors $a$ and $b$. The main drawback of GA is the randomness of the solution who changes a bit in the simulation is run again. Moreover, the result that we got is not at the optimal point yet because GA only searches on very small part of the total subspace. Therefore, for the future work, we will try to find one initial result that is close to the optimal result and set it as a starting point for the GA optimization. In addition, with good setting of boundaries, we can give a good range for the algorithm to converge. In future work, several real load profiles (at least 4 to represent working days and weekends/holidays for both dry and rainy seasons) and PV curves (available in [29]) will be considered. Some uncertainties on the behaviours of the load and productions profiles will be added to assess their impacts on the final topology as well as PV and batteries location and size. Also, a sensitivity analysis of the capacity of the diesel generator will be added.

\section{REFERENCES}

[1] R. Dave, S. Keller, B. Koo, G. Fleurantin, E. Portale, and D. Rysankova "Cambodia - Beyond connections: energy access diagnostic report based on the multi-tier framework", Washington, D.C.: World Bank Group., 2018.

[2] V. Vai, "Planning of low voltage distribution system with integration of PV sources and storage means - Case of power system of Cambodia", Ph.D. dissertation, Univ. Grenoble Alpes, 2017.

[3] P. Ciller, et al., "Optimal electrication planning incorporating On-and Off-grid technologies: The Reference Electrification Model (REM)", Proceedings of the IEEE, vol. 107. no. 9, pp. 1872-1905, 2019.

[4] V. Vai, M.-C. Alvarez-Herault, B. Raison, and L. Bun, "Optimal lowvoltage distribution topology with integration of PV and storage for rural electrification in developing countries : A case study of Cambodia", $J$. Mod. Power Syst. Clean Energy, vol. 8, no. 3, pp. 531-539, 2020.

[5] C. Vilá, M. Martinez, H. Fontana, D. Rodrigues, J. Anduaga, and D. Vila, "Rural electrification in Brazil based on microgrids", in 25 th International Conference on Electricity Distribution, 2019.

[6] K. Murugaperumal and P. Ajay D Vimal Raj, "Feasibility design and techno-economic analysis of hybrid renewable energy system for rura electrification”, Sol. Energy, vol. 188, pp. 1068-1083, 2019.

[7] J. Li, P. Liu, and Z. Li, "Optimal design and techno-economic analysis of a solar-wind- biomass off-grid hybrid power system for remote rural electrification : A case study of west China", Energy, vol. 208, no. Jul, p. 118387,2020

[8] R. Khan and N. N. Schulz, "Cost optimization of hybrid islanded microgrid for rural electrification", in IEEE Power \& Energy Society General Meeting, 2019, pp. 1-5.

[9] C. Tsai, T. M. Beza, E. M. Molla, and C.-C. Kuo, "Analysis and sizing of mini-grid hybrid renewable energy system for islands", IEEE Access, vol. 8, no. Apr, pp. 70013-70029, 2020.

[10] L. M. Halabi and S. Mekhilef, "Flexible hybrid renewable energy system design for a typical remote village located in tropical climate", J. Clean. Prod., vol. 177, no. Dec, pp. 908-924, 2018.
[11] M. M. Kamal and I. Ashraf, "Optimal resource allocation of rural microgrid using linear and non-linear algorithm", in International Conference on Electrical and Electronics Engineering (ICE3), 2020, pp. 252-257.

[12] A. L. Bukar, C. W. Tan, and K. Y. Lau, "Optimal sizing of an autonomous photovoltaic/wind/battery/diesel generator microgrid using grasshopper optimization algorithm", Sol. Energy, vol. 188, no. Jun, pp 685-696, 2019.

[13] M. Aqeel, Z. Liu, A. Alizadeh, S. Nojavan, K. Jermsittiparsert, and D. Zhang, "Designing an optimized configuration for a hybrid PV/diesel/battery energy system based on metaheuristics : A case study on Gobi Desert”, J. Clean. Prod., vol. 270, no. Jun, p. 122467, 2020.

[14] J. Namaganda-Kiyimba and J. Mutale, "An optimal rural community PV microgrid design using mixed integer linear programming and DBSCAN approach", SAIEE Africa Res. J., vol. 111, no. 3, pp. 111-119, 2020.

[15] N. Toma, O. Ivanov, B. Neagu, M. Gavrila, and S. Member, “A PSO algorithm for phase load balancing in low voltage distribution networks", in International Conference and Exposition on Electrical and Power Engineering, 2018, pp. 857-862.

[16] O. Ivanov, B. Neagu, M. Gavrilas, G. Grigoras, and C.-V. Sfintes, "Phase load balancing in low voltage distribution networks using metaheuristic algorithms", in International Conference on Electromechanical and Energy Systems (SIELMEN), 2019.

[17] G. Grigoras, M. Gavrilas, B. Neagu, O. Ivanov, I. Triștiu, and C. Bulac, "An efficient method to optimal phase load balancing in low voltage distribution network", in International Conference on Energy and Environment (CIEM), 2019, pp. 323-327.

[18] A. Naderipour, H. Saboori, H. Mehrjerdi, and S. Jadid, "Sustainable and reliable hybrid AC / DC microgrid planning considering technology choice of equipment", Sustain. Energy, Grids Networks, vol. 23, no Sep, p. 100386, 2020.

[19] A. M. Sallam, H. M.A. Ahmed, and M. M. A. Salama, "A planning framework for AC-DC bilayer microgrids", Electr. Power Syst. Res., vol. 188, no. Nov, p. 106524, 2020.

[20] https://enerbird.com/en/ems-enerbird/

[21] M. Sakarovitch, "Optimisation combinatoire, Méthodes mathématiques et algorithmes, Graphes et programmation linéaire”, Hermann, 1984.

[22] R. M. Ciric, a. P. Feltrin, and L. F. Ochoa, "Power flow in four-wire distribution networks-general approach", IEEE Trans. Power Syst., vol. 18, no. 4, pp. 1283-1290, 2003.

[23] W. S. Tan, M. Y. Hassan, M. S. Majid, H. A. Rahman, "Optimal distributed renewable generation planning: A review of different approaches" in Renewable and Sustainable Energy Reviews, vol 18, pp. 626-645, 2013.

[24] Homer, "HOMER - Hybrid Renewable and Distributed Generation System Design Software", 2015. [Online]. Available: http://www.homerenergy.com/.

[25] https://power-calculation.com/generator-diesel-energy-calculatorgenset.php\#consumptionvalues;

[26] EcoSun, "EcoSun Solar Appliance Products," 2017. [Online]. Available: http://ecosun-products.webs.com/.

[27] R. Fu, D. Feldman, and R. Margolis, "U.S Solar Photovoltaic System Cost, Technical Report", U.S National Renewable Energy Lab (NREL), NREL/TP-6A20-72399, 2018.

[28] C. Lao, and S. Chungpaibulpatana, "Techno-economic analysis of hybrid system for rural electrification in Cambodia", in Energy Procedia, vol 138, pp. 524-529,2017.

[29] pvwatts.nrel.gov 